\title{
DIREITO COMMERCIAL.
}

\section{A FALTA LE PROTESTO DESOBRIGA O SACADOR?}

\section{PARTE PRIMEIRA}

A evolução operada no direito cambial dos paizes, que imitaram a legislação franceza, exige uma rapida noticia da letra de cambio, considerada em suas differentes phases, antes de estudar a responsabilidade do sacador, quando o portador não tira opportunamente o protesto.

$\mathrm{Na}$ troca de moeda, realisada na mesma praça, consistia a primeira fórma cambial; e, mais tarde, com o desenvolvimento da industria mercantil, na permuta de dinheiro entre praças differentes.

Primum genus cambii, dizia SCACCIA,-est de pecunia prosenti cum pecunia prosenti: secundum,-est quod fit de pecunia prosenti cum pecunia absenti. ( ${ }^{1}$ )

No primeiro caso, dava-se uma pura e simples permuta manual de dinheiro (cambium manuale), no segundo, uma fórma escripta, que exprimia uma delegação (cambium per litteras), com a intervenção de quatro pessoas: um devedor e um delegante, um credor e um delegatario. $\left({ }^{2}\right)$

(1) De Commerciis et cambiis, Quœst. 4. a. PoTHIer, Traité du contrat de change, $n .1$.

$\left({ }^{2}\right)$ A. Marghieri, Svilluppo dell'instituto cambiario nella scienza e nella legge (1876), pag. 121. 
Esta especie de cambio foi tambem empregada, no correr dos tempos, como um meio de pagamento, alargando-se o conceito, que os antigos cultores do direito mercantil formavam, acerca do cambio trajecticio (cambium trajectitium). ( ${ }^{1}$ )

As relações commerciaes, augmentando-se rapidamente, evidenciaram as difficuldades occasionadas pelo contracto cambial, como era instituido (cambium per litteras), determinaram o apparecimento de uma nova entidade, concluindo-se, então, entre tres pessoas:sacador, sacado e portador (mercantile trajectitium).

As relações fundamentaes d'essa operação eram: - o valor e a provisão.

Pagavel em um lugar diverso d'aquelle em que foi emittida, a letra de cambio,--instrumento d'esse contracto, era a expressâo d'esses dois elementos, sem os quaes não podia existir. $\left({ }^{2}\right)$

Circumscrevendo-se á remessa de dinheiro de praça á praça, o contracto de cambio não tardou a extender-se a quaesquer outros valores, comprehendidas as mercadorias, entendendo-se existir provisão sempre que o sacado fosse, na occasião do vencimento da letra de cambio, devedor da somma constante da mesma.

"Una altra novità, escreveu GalluPPI, um dos mais notaveis commercialistas italianos, s'introdusse nella cambiale in ciò, che fu ammesso poter la cambiale servire anche come documento di cambio trajettizio di merci $e$ di altri valori, mentre originariamente non poteva servire che come documento esclusivo di cambio trajettizio di moneta. $\left({ }^{3}\right)$

A introducção da clausula á ordem, no decurso do XVII seculo, e pela primeira vez consagrada

(1) Galuppr, Dir. Com. Vol. 1.0 pag. 355.

(2) Supino, Dir. Com. Cap. X. $\$ 1.0$

Franchi, Dir Com. Ital. pag. 249.

(3) Marghieri, La Cambiale, pag. ̃. 
legislativamente na Ordenança de 1673, imprimiu na letra de cambio a grande vantagem de poder mais rapidamente ser transferida, mediante o endosso, e mais garantida, por meio do aval.

A letra de cambio, pois, symbolisa o contracto de cambio trajecticio, e depende, além de outros requisitos, do valor e provisão, como ficou assignalado.

$O$ valor e a provisão, considerada a letra como instrumento do contracto de cambio, são instituições cambiarias. $\left({ }^{1}\right)$

Dos principios estabelecidos, se póde concluir, que - contracto de cambio é aquelle pelo qual uma pessoa, que recebe n'um lugar uma somma de dinheiro, ou outro valor, se obriga a fazer pagar á pessoa, que lha entrega, uma somma de dinheiro em outro lugar. $\left({ }^{2}\right)$

D'esta noção dimana, que são elementares d'esse contracto :

A) que uma das partes se obrigue para com a outra a lhe pagar uma somma de dinheiro, e não de outros valores; $\left({ }^{3}\right)$

B) que a remessa se effectue de praça a praça. A letra de cambio, encarada como instrumento contractual, não satisfazendo as aspirações da sciencia, nem preenchendo as necessidades da vida commercial, preoccupou por muito tempo o espirito dos juristas, até que Schmalz, em 1805, inspirado nos escriptos de Azuni, procurou isolal-a do contracto de cambio

(1) GalluppI, cit. pag. 390 .

$\left({ }^{2}\right)$ Ferreira Borges, limitando o contracto de cambio á remessa de uma somma de dinheiro, na definição dada, no Dic. jur. Com., approximou-se de BALDUs:-contractus pecunice emtce et venditce (Consilia III, 100) mas ficou aquem da verdadeira concepção do direito cambial, que a extende a quaesquer valores.

"Dare in un luogo determinato una somma di danaro o ALTRo VALORE in cambio di una somma di danaro, diz GallupPI, cit. pag. 359.

$\left({ }^{3}\right)$ E' por isso, que TuRRT denomina o contracto de cambio,-contractus pecuniavius 
trajecticio, para consideral-a papel-moeda dos negociantes. ( ${ }^{1}$ )

"Imperfettamente, advertia AZUNI, si conoscerebbe l'utilitá della lettera di cambio, se si volesse considerare in essa la sola funzione di facilitare il transporto.

- Essa ne fa tutte le funzioni, ed è come il danaro stesso nelle mani dei negozianti, il sicuro rappresentativo del valore di ogni cosa, col vantaggio ancor più grande del canaro da lei dato, per la facilità e rapidità del trasporto, tenendo luogo per ogni dove di numerario $e$ dando l'attività alla circolazione delle derrate e merci di ogni paese». $\left({ }^{2}\right)$

Os fundamentos da theoria moderna, relativamente á cambial, já estavam lançados, quando os juristas allemães procuraram dar-lhe uma feição especial, desenyolvendo com segurança maior os assertos encontrados na obra monumental do commercialista italiano

Einert $\left({ }^{3}\right)$, desenvolvendo os escriptos de seus predecessores, julga, "que a cambial não exprime um contracto, e sim acha o seu destino em si propria. Ella é o papel-moeda do commerciante, fundado sobre o credito mercantil, e o seu objecto consiste em ser negociada como meio de pagamento".

"E' semelhante a um titulo ao portador, em que o emissor não se obriga para com pessoa determinada, senão para com o publico inteiro, como principal devedor.»

(1) Kleine Schriften über Recht und staat (Halle 1805 p. 1. pag. 183).

(2) Dizionario, voce Lettera di cambio. Os juristas allemães attribuem, geralmente, aos exforços de SchMalz, EICHнORN, (Einleitung in das deutsch Privaterech mit Einschluss des Lehnrechts, Gottinga, 1836; e TreITSCHKe Alphabetische Encyclopädie del Wechselrecht und Wechselgesetze, Leipzig. 1831), a moderna concepção da cambial: jorém BRANCCACIO (Sull'ultimo progetto di legge cambiaria italiana) com toda a razão reivindica essa gloria para a patria de Azunı.

$\left({ }^{3}\right)$ Das Wechselrecht nach den Bedürniss des Wechselgeschäfts im neunzehnten Jahrhundert. 
A doutrina exarada por este jurista, em sua notavel obra intitulada-O Direito de cambio, segundo as necessidades do commercio cambial no XIX seculo, é reputada pelos modernos commercialistas, - u u momento exclusivamente theoretico ( $\left.{ }^{1}\right)$; porque, abalando profundamente as bazes do direito cambial, elimina a responsabilidade daquelles que podem figurar na letra de cambio. $\left({ }^{2}\right)$

Töhl, Renaud, Gierke, e Goldschmidt, depois das observações de MitTermayer $\left({ }^{3}\right)$, concernentemente á theoria de EINert, confutando-a vantajosamente, demonstram a evidencia, que a obrigação cambial não descende da simples subscripção, mas sim de um outro momento, ou circumstancia exterior; não surge da entrega unilateral da letra de cambio, porém de um verdadeiro contracto passado entre o sacador e o portador, com a reciproca vontade da entrega e acceitação do titulo. $\left({ }^{4}\right)$

A opinião, professada ardentemente por GoLDsCHMLDT, predominou alfim, - perchè, como escreveu Franchi, admiravel jurista, principalmente pela sua concisão, difficilmente si può sostenere il caraltere di atto unilaterale, dove è necessario che intervegna, altre la trasmissione, l'accettazione del titolo da parte del. creditore.» $\left({ }^{5}\right)$

(') A. Marghieri cit. Sviluppo dell'istituto cambiario pag. 121. Calamandrei (La cambiale pag. 18) espósa a opinião de EINERT.

(2) Schlossmann deriva a obrigação, não directamente da promessa de pagar, mas sim da falta de pagamento do titulo creditorio emittido.

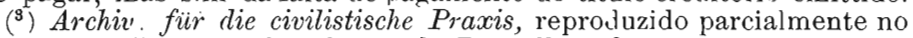
archivo de Direito e legislação, de Bruxellas 1843 .

(4) FraNCHI cit. n.o 115 .

(5) A. MARGHIERI, (I motivi del codice di commercio italiano, vol.2.o, Parte seconda) transcreve um parecer, em que se pretende provar, que a letra de cambio, como obrigação formal, remonta an tempo dos Romanos. Procura-se argumentar com a litterarum obligatio, não como foi entendida por Justiniano, no tit. 22 do Liv. III das Institutas, mas sim como foi encarada por Gaio (Liv. III $\$ 128$ e 137), e nas paraphrases de Theophilo:-litteris obligatio fit, veluti in nominibus transcriptitiis, Lyon-Caen \& Renault, porém, pensam, que: -il ne semble pas qu'elle remonte au de lá du moyen âge. 
A cambial não é o instrumento do contracto de cambio, mas gera um contracto, pelo unico facto de ser negociada, produzindo um vinculo de solidariedade, que prende aquelles, que n'ella figuram. A obrigação assenta, pois, em um contracto formal, que se torna perfeito pela entrega do titulo, feita pelo emissor, e o recebimento por parte do tomador.

A letra de cambio, como obrigação formal, "de pagar, ou authorisar o pagamento de uma somma, em lugar, e vencimento determinados, ao possuidor della:, tem uma existencia propria, funccionando economicamente como titulo de credito, como instrumento multiplicador das permutas, semelhante aos bilhetes bancarios, destinados tambem a preencher os mesmos fins. ( ${ }^{1}$ )

Assim considerada, passou a mesma para a lei germanica de 1848, e não como inculcam LyoN CAEN \& Renault $\left({ }^{2}\right.$ ) a theoria insustentavel de Einert, que mutila a instituição cambial.

Comprebende-se, facilmente, que a cambial, como uma obrigação formal, dispensa as remessas de praça a praça, de valor recebido, e de provisão de fundos.

As questões de valor e de provisão, tão importantes no contracto de cambio trajactecio, ficam reduzidas, ou a simples ficções, ou a relações meramente pessoaes entre sacador e sacado, e, por isso, extrauhas á cambial.

"Il n'est plus necessaire, escreve V Rossel, $\left({ }^{3}\right)$ comme le voulait l'art. 110 du Cod. de com. fr., ni de la remise de place en place, ni laro connaissance de la valeur fournie, cette reconnaissance n'étant d'ailleurs pas sincére, la plupart du temps; la provision n'est donc plus une condition fundamentale de la validité de la lettre de change.

(1) Vidari. La cambiale, n. 25, 27 e 28. Galuppi cit. n. ${ }^{0} 243$

(2) Des lettres di change, n.o 45 .

(3) Droit Federal des obligations (1892), n. ${ }^{0} 952$. Caramandrer, La Cambiale, n.o 27. 
O systema acolhido pela legislação germanica, tem exercido poderosa e proficua influencia em todas as reformas, recentemente effectuadas no direito cambial dos paizes adiantados, como a Austria, Hungria, Belgica, Hespauha, Inglaterra, Italia, Portugal, Romania, Scandinavia, Suissa, Estados-Unidos e Egypto.

Em França, o movimento reformador foi iniciado, e já existe um projecto de lei, tendente a modificar os arts. 110,112 e 632 do C. Com., segundo noticiam Lyon-Caen \& Renault $\left({ }^{1}\right)$, no sentido de harmonisar a legislação cambial com os principios, e com as praticas do commercio geralmente recebidas.

Entre nós, as disposições pertinentes á letra de cambio, resentindo-se dos mesmos defeitos deparados na legislação franceza, continuam refractarias aos progressos introduzidos nas leis mercantis dos povos cultos, imitando de tal arte a immobilidade da Grecia e da Turquia, no tocante ao direito cambial.

(') Rapport de M. Marty à la Chambre des députès (N.o 300); de M. Marquis au Sènat (N.o 169). Conf. Fremery, Etudes de droit Commercial (Paris 1833).

Legislação comparada. - Estudando as diversas legislações, sob o ponto de vista dos requisitos e enunciações, que a letra de cambio deve conter, conclue-se sem difficuldade, que ellas adoptam tres differentes systhemas:

1.0) O francez, tambem seguido na Hollanda, Brasil e Chile; - a remessa de praça a praça, o valor e a provisão são exigidos, porém é desnecessaria no titulo a expressa declaração de letra de cambio;

2.0) O allemão, acceito nas leis hungara e escandinava sobre o cambio, nos codigos de com. italiano e suisso, das obrigações; dispensa a remessa de praça a praça, a declaração de valor e provisão. Exige, porém, a menção de letra de cambio;

3.0) O anglo-americano, consagrado na lei ingleza, leis e usos dos Estados- Ćnidos, codigo do commercio portuguez, e legislacão cambial belga; não requer a enunciação de praça á praça, de valor recebido e provisão de fundos, nem a denominação de lettra de cambio.

O Codigo commercial hespanhol de 1885, de accordo com os dois ultimos systhemas, repelle a condição de remessa de praça á praça: como o primeiro e o terceiro, não exige a denominação de letra no ins. trumento, mas prescreve a indicacão de valor recebido, a exemplo do francez. Comıp. Lyon Caen \& Renault. cits N.0 62. 


\section{PARTE SEGUNDA}

«Il sistema cambiario del nostro Codice é " un sistema vecchio, combattuto, e che poco " altro tempo potrà reggere a fronte dei pro" gressi e dello svilupparsi del commercio".

Galluppi, Diritto Commerciale.

O notavel jurista allemão, Kuntze ( ${ }^{1}$ ) divide em trez epochas os progressos da instituição cambial, denominando, - italiana a primeira, em que a cambial era um meio de permuta; franceza a segunda, attingindo á promulgação da lei germanica sobre cambios, em 1848, em que a letra era reputada um modo de pagamento, em serviço dos negociantes; e allemã a ultima, em que é considerada um titulo de creditó, em beneficio de todos.

O nosso Codigo Commercial occupa um lugar rio periodo intermedio. A letra cambial, regulada no Tit. XVI, cap. $1 .^{\circ}$, da primeira parte, é ainda um instrumento do contracto de cambio trajecticio, como acontece na legislação mercantil franceza, e acontecia no dominio do codigo italiano de $1865\left({ }^{2}\right)$.

A remessa de praça á praça, a menção de valor recebido, a provisão de fundos, são elementares da cambial, em frente do direito mercantil patrio.

E' por isso, que o Art. 354 n. ${ }^{\circ}$ III do Codigo Commercial estatue, que a mesma, além de outros requesitos, deve declarar: - o valor recebido, especificando se foi ern moeda, e a sua qualidade, em mercadorias, em conta ou por outra qualquer maneira»; e que o art. 366 determina:-- que o sacador é obrigado a ter sufficiente provisão de fundos em poder

(1) Handbuch di Endemann Vol. IV, par. 2. ${ }^{a}$

(2) Śupino cit. pag. 246:-La cambiale passò nel Codice Francese, e successivamente in quello italiano del 1865, col carattere di prova del contratto di cambio trajettezio. 
do sacado, ao tempo do vencimento; pena de responder por perdas e damnos supervenientes, se por falta de provisão sufficiente, feita em devido tempo, a letra deixar de ser acceita ou paga, emquanto esta não prescrever (Art. 443) ainda que não tenha sido protestada em tempo e fórma regular (Art. 381).

$\mathrm{E}$ no art. 368 estabelece regras, attinentes á provisão, que: "entende-se existir em poder do sacado, quando este, ao tempo do vencimento, é devedor ao sacador, ou áquelle por conta de quem a letra foi passada, de quantia ao menos egual, ou quando qualquer dos dois tiver credito aberto pelo sacado, que baste para o pagamento da letra s (Art. 392) ( ${ }^{1}$ ).

A provisão de fundos é, na esphera do direito mercantil patrio, uma instituição cambial de grande importancia nas relações juridicas entre sacador e sacado.

Obrigado a habilitar o sacado a solver o saque, o sacador não se libera da responsabilidade, ainda mesmo "que a letra não tenha sido protestada em tempo e fórma regular», emquanto não provar a provisão de fundos. (Cod. Com. Art. 369).

Essa prova incumbe ao sacador, ainda mesmo quando o sacado acceitasse a letra. Entretanto, VIDARI $\left({ }^{2}\right)$, appellando para o art. 117 do Cod. Com. fr. e 369 do Cod. bras., sustenta, que o acceite, induzindo a provisão transfere ao acceitante o dever de destruir a presumpção, que d'esse acto dimana.

E' verdade que o art. 117 do Cod. Com. Fr. prescreve:-Liacceptation suppose la provision; mas termina, estatuindo que;-le tireur seul est tenu de prouver, en cas de denegation, que ceux sur qui la lettre

(') E' inefficaz a provisão existente ao tempo do saque e que desappareceu ao do vencimento; ou que foi feita depois do vencimento; assim como a incompleta, ou constante de um credito não vencido, quando o sacado quizer aproveitar-se do praso. LYON-CAEN \& RENAULT cits. n. 163 e segs.

${ }^{(2)}$ Dir. Com. cit. n. 6.901. 
était tirée avaient provision á l'écheance, sinon il est tenu de la garantir, quoique le protet ait áté fait aprés les delais flxés.» (1)

Explanando esse conceito legal, Alauzet $\left({ }^{2}\right)$ affirma que: : il est certain, que l'acceptation ne peut prouver la provision dans les rapports du tiré avec le tireur; $\mathrm{e}$, em seguida, que: "cette justification ne peut, en aucun cas, être imposée qu'au tireur seul.»

Si pelo direito francez a obrigação de provar a provisão incumbe ao saccador, como ficou assignalado; em face da legislação commercial brasileira, não é menos certo, que, tendo ella supprimido a primeira parte do art. 117 prec., isto é, que, "l'acctptation suppose la provision", por mais força de razão, o encarregasse de justifical-a. $\left({ }^{3}\right)$

$\mathrm{O}$ art. 369 do Cod. Com. invocado por VIDaRI, ao envez de transmittir ao acceitante a prova, de que não estava habilitado a cumprir o saque, expressamente determina, que: "o sacador é responsavel pela importancia da letra a todas as pessoas, que forem successivamente adquirindo a sua propriedade até ao ultimo portador ", cessando a responsabilidade, quando a letra não fôr apresentada, ou protestada em tempo e forma regular, "uma vez que prove, que tinha sufficiente provisão de fundos em poder do sacado ao tempo do vencimento.

Apezar de claras e terminantes as disposições legaes precitadas, alguns juristas irreflectivamente têm

(1) En principe, dizem Lyon CAEN \& Renaum, le tireur est tenu; pour echapper á son obligation, il doit prouver qu,ll a droit á l'exception prévue par la loi, c'est-á-dire qu'il a fait provision, et il fait cette preuve par les moyens ordinanaires, notamment par ses livres, par sa correspondence, MAIS IL NE SUFFIT PAS D'INVOQUER L'ACCEPTATION DU TIRÉ. (n. 408)

(2) Com. du Cod. de Commerce, vol 4.o, pag 106. Bedarride, De la Lettre de change n. 523. Novgurer, Let. de change, vol 1., n. 379.

${ }^{3}{ }^{3}$ O Cod. Com. Argentino, art. 8:6 dispõe: - que pelo acceite não se presume a proviscio. 
entendido, que a falta de protesto exonera indistinctamente o sacador. ( $\left.{ }^{1}\right)$ Referem o art. 381 do Cod. Com., que prescreve: o portador que nâo tira em tempo util e fórma regular o protesto da letra não acceita, perde todo o direito e acção contra os endossadores, e só conserva contra o sacador; sendo, porém, o protesto de falta de pagamento, perde todo o direito contra o sacador $e$ endossadores, $e$ só conserva contra o acceitante; salvo no caso prevenido nos arts. 367 e 368 , em que o conserva tambem contra o sacador, e contra aquelle por conta de quem a letra foi passada», adduzindo, que o direito do portador contra o sacador, quando a letra acceita não fôr protestada, persiste sómente nos casos exceptuados pela disposição transcripta, não podendo, sem prejuizo das expressões positivas da lei, extender-se á especie prevista no art. 366 do mesmo codigo; pois que a menção dos arts. 367 e $368 \mathrm{im}$ porta virtualmente a sua exclusão. $\left({ }^{2}\right)$

O Art. 381, regulando duas hypotheses differentes, resguarda, na primeira, o direito do portador contra o sacador, quando elle deixa de tirar em tempo util e fórma regular o protesto da letra não acceita, perdendo todavia a acção contra os endossantes; na segunda, accentúa a responsabilidade do acceitante, na ausencia de protesto por falta de pagamento, parecendo desobrigar o sacador e endossantes.

(1) «Sendo o saque por conta de terceiro, a este incumbe fazer a provisão de fundos em tempo competente, sem que o sacador deixe de ser solidariamente responsavel ao portador e endossados pela segurança da mesma letra, na fórma do art. 366. (Cod. Com. art. 367) BENTEJAC, Etude sur la provision, n. 28.

Por extranhas a estas ligeiras observações, deixamos de esmerilhar as interessantes questões, que o mencionado art. 367 suggere; notadamente com respeito a responsabilidade do terceiro por cuja conta é sacada a letra de cambio, no organismo do direito moderno.

(2) A opiniāo d'esses juristas predominou por longo tempo, muito embora originada de uma apreciação erronea da lei; e, reflectindo na jurisprudencia, imperou no Tribunal do Commercio da Côrte, até 1863. (Orlando, Quarta Edição, 1886, not. 529. Pinheiro, Jur. Com. pag. 139). 


\section{$-148-$}

Mas as disposições legaes, como muito bem adverte Thiвıut, ( $\left.{ }^{1}\right)$ não podem ser entendidas de maneira que umas supprimam as outras; e sim interpretadas de modo a guardarem a harmonia, que deve existir no contexto de toda lei.

E' verdade, que o a Art. 381 não exceptua o Art. 366, mas é inquestionavel, que este conceito legal se refere expressamente áquelle.

E si o Art. 366 consagra a responsabilidade do sacador, que não tiver provisão de fundos em poder do sacado ao tempo do vencimento "ainda que a letra não tenha sido protestada em tempo e fórma regular. é claro, que o Art. 381 não podia extinguil-a sem incidir em manifesta contradicção, contra todas as regras da analytica juridica.

Torna-se preciso interpetral-os, para conservar a harmonia, que deve reinar entre as disposições de uma lei. E, então, só resta ao interprete um alvitre - subordinar a segunda parte do Art. 381, á ultima do Art. 366. O portador, que não tirar em tempo util e fórma regular o protesto de não paga, perderá o direito contra os endossantes, e conserval-o-ha contra o acceitante, e contra o sacador, sempre que este não prove provisão de fundos.

Só assim poder-se-á explicar as ultimas expressões do Art. 366, "ainda que não tenha sido protestada em tempo e fórma regular."

O Reg. 1. ${ }^{\circ} 737$, de 25 de Nov de 1850, no Art. $372 \S 2 .^{\circ}$ corrobora a intelligencia dada ás prescripções do Codigo Commercial, quando dispensa o protesto: "contra o sacador, se a letra não foi acceita, ou se deixou de ser paga, porque elle, ou o terceiro por cuja conta a sacou, não fizeram a provisão de

(1) Dell'Interpretazione Logica, Ver's. de Marinis 
fundos ao tempo do vencimentos, reportando-se aos Arts. 366, 368 e 381 do Codigo ( $\left.{ }^{1}\right)$

Teixeira de Freitas $\left({ }^{2}\right)$, dando egual interpretação ao Art. 381 do Cod. Com., pensa que: embora o mesmo não se refira ao Art. 366, refere-se este áquelle, dizendo:- ainda que não tenha sido protestada em tempo e forma regular. No evento, pois, de--letra acceita e não paga-, o portador, além de seu direito contra o acceitante, tem-n'o mais contra o sacador omisso na provisão de fundos, sem embaracal-o a falta ou a irregularidaide do protesto».

A falta de protesto, portanto, exonera sómente o sacador que, ao tempo do vencimento da letra, tiver sufficiente provisão de fundos, opportunamente feita, em poder do sacado.

A jurisprudencia patria, como aconteceu na Italia, quanảo vigorava o Codigo Commercial de $1865,\left({ }^{3}\right)$ tem procurado attenuar o vigor do nosso direito cambial, interpretando as disposições retrogadas da legislação respectiva, de accordo com as leis e costumes dos povos adiantados. Para isso, porém, os tribunaes têm sido obrigados a mutilar o systema

(1) Legislação comparada. O systema adoptado no direito patrio já era consagrado pela Ordenanca de 1673, donde passou para o art. 170 do Cod. Com. Frc., e é admittido no art. 108 do Cod. Hol. ; 83 da L. All.; 90 da L. Hung.; 69 da X. Belg.; 813 do C. S. das Obrig. ; 326 do Cod. Ital. ; 351 do Cod. Rom., e 702 do Cod. Chil.

Mais severa era ainda a referida Ordenança, porque, si a lei mercantil patria exige, que o sacador prove a provisão de fundos em poder do sacado, aquella extendia essa obrigação aos endossantes. (Tit. V., art. 15).

(2) Add. ao Cod. do Com., Vol. 1.o, pag. 749.

(3) Fortunatamente le idee scientifiche, observa A. Mar(iHIERI possono seguire tranquille il loro corso malgrado le leggi. Giacchè queste quando vamno a ritorso dei fatti che sono chiamati a regolare, non hanno l'efficacia d'impedire che essi non la eludano, mascherandosi sotto forma che apparentemente rispondono ai loro dettati $e$ continuando, per una necessità fatale pii forte di ogni legge, a vivere ed allargarsi, a formare mano mano la base del vero movimento economico insieme e scientifico (cit. pag. 107). 


\section{$-150-$}

cambial adoptado pelo Codigo do Commercio, isolando a letra de cambio do contracto, que lhe dá causa.

Seria, pois, de grande conveniencia reformar a legislação cambial, afin de uniformisal-a com a dos paizes, que têm acompanhado os progressos do direito commercial, satisfazendo de tal arte ás aspirações generosas do commercio internacional, e aos exforços ingentes dos que se dedicam á carreira mercantil.

Dr. A. J. Pinto Ferraz. 